\title{
The importance of training and certificates in the access of university graduates to the labour market
}

\author{
Bartosik Artur \\ Kielce University of Technology, Kielce, Poland \\ Wiścicka Dorota \\ Pragmatic Ltd., Kielce, Poland
}

\begin{abstract}
In the era of growing competitiveness on the labour market, it has become common for students and graduates of higher education institutions to participate in various types of training courses and obtain various types of certificates, which are an additional asset when applying for employment. The interaction of a university with the environment requires constant monitoring of the expectations of labour market. Therefore, the main objective of the paper is to analyse of labour market requirements on additional certified competences of graduates during their studies. The paper attempts to answer the question: whether, and if so, to what extent the training received and the certificates obtained by the potential employee are important from the employer's point of view. The matters raised in it are a contribution to the discussion on the issue of needs and preferences of employers, including the most important aspects that guide them during the recruitment process. The study presents the results of surveys aimed at analysing the preferences of entrepreneurs and other entities in relation to the competences of graduates of universities. The survey method was chosen from among the empirical research methods used, which is characterized by a nomothetical approach, aimed at seeking generalized judgments, laws and rules for a certain class of situations or events. The survey covered not only entrepreneurs, but also representatives of other entities. Random sample selection was adopted for the conducted surveys. Setting the acceptable margin of statistical error at $e=5.5 \%$, for confidence level $\alpha=0.80(Z=1.28)$, response distribution $f=0.5$ and population size $N_{p}=107.798$. It has been calculated that the minimum research sample should consist of $\mathrm{N}_{\text {min }}=136$ employers. The draw was conducted on the basis of a list of all entities of the Swietokrzyskie Region in Poland. The collected quantitative data were analysed. The survey results indicated that employers pay attention to certificates, qualifications, courses and trainings obtained by university graduates. Additionally, graduates should demonstrate some professional experience, therefore student apprenticeships and practical profiles of education are also important. Respondents emphasized the problem of the deficit of the skills of applying knowledge in practice by university graduates, stating the ubiquitous excess of theory over practice.
\end{abstract}

Keywords

labour market requirements, lifelong learning, graduate's expertise, certification of competences

\section{Introduction}

The labour market and phenomena related to it are the subject of many analyses and scientific studies. An efficiently functioning labour market is one of the basic pillars of the economy, enabling the utilization of existing labour resources and the human capital accumulated in them. This study takes into account the labour resources limited to the category of university graduates and analyses them from the point of view of employers in terms of their needs and preferences, including the most important aspects that guide employers in recruiting new employees. Developing possibilities to gain a new competence by students is the main goal of modern university. This requires building a support system for entrepreneurial attitudes 
among students. Such a system can include various actions oriented to talented students (Bartosik, 2017).

Reports published as part of the research project "Balance of Human Capital", implemented by the Polish Agency for Enterprise Development in cooperation with the Jagiellonian University since 2009 - invariably show the unfavourable situation of university graduates on the labour market. A university degree, which used to be a springboard for a career, now requires additional certificates. These are primarily the effects of the educational change, which consisted in the massification of higher education (Kwieciński, 2012).

Since the beginning of the social and economic transformation in Poland, a significant increase in interest of young people in pursuing higher education can be observed. In 1989, 378 thousand people studied in Poland (Statistical Yearbook of the Republic of Poland, 1990), and in the record year 2005 - as many as 1.95 million (Statistical Yearbook of the Republic of Poland, 2006), (an increase by $416 \%$ ). Since then, the number of students has decreased to 1.23 million in 2018 (Statistical Yearbook of the Republic of Poland, 2019), (through 1.84 million in 2010 (Statistical Yearbook of the Republic of Poland, 2011), and 1.41 million in 2015 (Statistical Yearbook of the Republic of Poland, 2016), but compared to the beginning of the 1990s, when economic transformation began, the number of people in higher education remains high. Although it is very often published that one of the main reasons for such an increase in Poland was the entry of the baby boomers of the 1970 s and $1980 \mathrm{~s}$ into the study age. Indeed, the statistical data indicate that in the years 19892004 there is a significant increase in the population aged 19-24, from 3 million (Statistical Yearbook of the Republic of Poland, 1990), to almost 4 million (Statistical Yearbook of the Republic of Poland, 2006), and then - since 2005, a decrease (Statistical Yearbook of the Republic of Poland, 2011), which is exactly in line with the trend in the number of students. The increase in the number of students was also influenced by the policy of public authorities, which started to appreciate the importance of higher education, not only in the sense of its impact on social and economic development, but also as a tool to reduce unemployment by postponing the entry of young staff into the labour market. The marketization of the economy has resulted in a change of priorities on the Polish labour market higher education has gained value, translating into good job offers and relatively good remuneration. To sum up - in the 1990s, higher education was seen as a safety net against unemployment, but today it no longer secures employment, but in the young generation it functions almost as a prerequisite for success on the labour market.

If we assume that the gross enrolment ratio remains at the same level as in 1990 and the increase in the number of students results exclusively from the numerical growth of the age category, i.e. $19 \div 24$ years of age, in $2004-$ the most numerous in terms of population at the age of 19-24 - there should be about 512 thousand students, and in fact there were 1.95 million of them (Statistical Yearbook of the Republic of Poland, 2006). It becomes clear that the direct impact of the demographic factor was small, and the increase in the number of students is also due to other reasons. Moreover, the increase in educational aspirations in the baby boomer cohorts generates a higher number of students than it would have been in the period of low birth rate (Moron, 2016).

The effect of the educational boom described above is an increase in the number of people with higher education. In 2005, 23\% of people aged 30-34 had higher education (Statistical Yearbook of the Republic of Poland, 2006), and in 2015 as many as 43\% (Statistical Yearbook of the Republic of Poland, 2016), with the EU average of 28 and $39 \%$ respectively. The target value of this index adopted for the implementation of the Europe 2020 Strategy is 45\%, which assumes maintaining a high level of the gross enrolment ratio for higher education. However, obtaining such an index in Poland requires creating conditions for undertaking higher education and increasing the chances of university graduates on the labour market.

$\mathrm{BHC}^{1}$ research shows that in the years 2001 2005 about 2.5 million people under the age of 30 entered the labour market. In this group, $43 \%$ of

\footnotetext{
${ }^{1}$ Balance of Human Capital $(\mathrm{BHC})$ - is one of the largest European research projects in the area of competences, employment and the labor market. Its aim is to monitor the demand among entrepreneurs in the above-mentioned area. The BHC is used for identification of areas of mismatch of competences by people of working age to the needs of the labor market. The results of the research are the basis for formulating recommendations for public policies in such areas as: science and education, the labor market, development of entrepreneurship. It provides valuable data on competence gaps in the economy and educational activity of adult Poles.
} 
them were university graduates, $38 \%$ were from schools ending with a maturity exam and $19 \%$ from schools not offering the maturity exam, i.e. basic vocational, middle or primary schools.

On the one hand, the gross enrolment ratio is increasing and on the other hand, the demand for specialists with higher education is decreasing. Unemployment among university graduates is rising. In 2001 there were $3 \%$ of unemployed university graduates, and in 2011 there were $12 \%$ and there is no indication that this trend will change much. Between 2010 and 2011, the demand for workers, fitters and operators increased from $40 \%$ to $50 \%$ and the demand for specialists decreased from $40 \%$ to $25 \%$ (Pinheiro \& Antonowicz, 2015)

Paradoxically, higher education has begun to deepen social divisions due to its massification. On the one hand, there are prestigious universities that give their graduates a chance to be a part of the middle class. On the other hand the overcrowding of the universities began to generate ever-increasing unemployment among holders of formal diplomas. It seems that the excess of people holding university diplomas does not bring profits to anyone, as both the graduates and employers do not have the expected benefit from them (Etzkowitz, 1998).

In view of the phenomenon of the inflation of diplomas, employers are trying to choose those candidates who will be competent. Competences, i.e. knowledge and skills acquired at school or at university, quickly become obsolete, due to the high dynamics of new technology development. The most recent BHC survey indicates that for most employers, the key criterion in selecting an employee is education (83\%), followed by experience $-69 \%$. Every fourth employer requires above all diligence, meticulousness, accuracy, responsibility, work discipline, honesty and credibility from candidates. Alongside education, soft skills are an important element in the search for employees. Among the most frequently mentioned are ease of establishment of relations with people, personal culture and selfpresentation, willingness to work, time management and punctuality (Czarniak et al. 2019; Bartosik et al., 2018; Wiścicka et al., 2018).

The main objective of the paper is to analyse labour market requirements on additional certified competences of graduates during their studies. The paper presents the results of a survey of entrepreneurs and other employers of the Swietokrzyskie Region in Poland. The paper emphasises importance of training and certification of graduates in accessing the labour market.

\section{Description of the Research Method}

\subsection{Research purpose}

The aim of the empirical research was to diagnose - on the market of the Swietokrzyskie Region the expectations of employers in relation to the competences of university graduates, with particular emphasis on the importance of certified trainings.

In particular, the study concerned the diagnosis of the actual state and recommendations to increase the effectiveness and accuracy of university management in terms of adjusting the program offer to the regionally differentiated labour market.

\subsection{Research method}

From among the applied research methods - to verify the above-mentioned research problem the questionnaire method was chosen, as those methods have a quizzing nature and are widely used, allowing to recognize the designated opinions of respondents in relation to specific socio-economic phenomena taking place in organizations (Altdorfer et al., 2003).

The questionnaire research method is a part of the group of empirical methods and focuses on solving the research problem from the experience side, by capturing conditions which are as close as possible to reality and which allow the researcher to explore the issue from the scientific side. By their nature, they are part of the nomothetical research approach, focused on the search for generalized judgments, laws and rules of the world of organizations, which is implemented through an inductive research path (mainly incomplete enumerative induction), which allows to determine the truthfulness of a phenomenon on the basis of sentences confirming its existence in some cases only (out of all possible). However, for this reason, it is an unreliable method and requires a certain methodological rigor, ensuring relatively high accuracy, reliability and objective conclusions.

Questionnaire research is currently one of the most popular empirical research methods, where a questionnaire tool is used to collect information from respondents. In principle, they may be of a 
verificative $^{2}$ or diagnostic ${ }^{3}$ nature. On the basis of the factual state of affairs established during the research, it is also possible to anticipate and formulate the directions of development of the examined issue. Therefore, the decision to utilize this method was based on the nature of the problem to be diagnosed, which was planned to be solved.

Prior to the research, a questionnaire was developed, which consists of basic information and 12 close-ended questions (including 4 single and 8 multiple-choice questions) concerning the current situation of the surveyed employers, as well as actions only planned by them (Bartosik, et al., 2018; Wiścicka et al., 2018).

The so-called mixed-mode data collection scheme was chosen as the form of data collection in order to increase the degree of sample completion, consisting in combining several information collection procedures (Altdorfer et al., 2003). In this research project, it has been decided to conduct an online survey by means of an electronic questionnaire to be filled in by the respondents, and to use a traditional paper version of the questionnaire in order to ultimately ensure that potential respondents can participate in the survey in the most convenient way for them. The location of the questionnaire on the website, apart from the possibility of constructing a convenient research tool, made it possible to control its course, giving the opportunity to monitor the level of sample execution, as well as to check the correctness and completeness of filled-in forms. The website address of the questionnaire was sent to the respondents by e-mail and via an instant messenger. Paper questionnaires were sent by post with a request for it to be filled in and sent back or delivered to the respondents and collected in person. The quantitative data obtained in the empirical study were analysed statistically.

\subsection{Sample selection criteria}

The adopted research objective has clearly and unequivocally translated into the criteria for the selection of the research sample. The survey covered not only entrepreneurs, but also representatives of other entities and institutions of the Swietokrzyskie Region, including hospitals

\footnotetext{
${ }^{2}$ The results of such a study may be the basis for confirming or rejecting the hypothesis, i.e. a presumed, predictable answer to the question contained in the research problem.

${ }^{3}$ The essence of this is to determine the characteristics or principles of functioning of a particular piece of reality.
}

and local government units. From the surveyed population of employers, entities from several sections of the Polish Classification of Business Activities 2007 were excluded, i.e.: households that employ workers, households producing goods and services for their own needs and extraterritorial organizations and groups; member organizations and foundations, churches, religious denominations, associations and other social organizations, political parties, trade unions, organizations of employers, economic and professional self-governments, housing communities and associations of agricultural producer groups. It was not possible to examine in detail the companies and institutions from these specific sectors and types of entities with the sample size assumed.

Random sample selection was adopted for the conducted surveys (Mccrum-Gardner, 2010), (Omair, 2014). By setting the statistical error margin of $e=5.5 \%$ (for confidence level $\alpha=0.80$ with $Z=1.28$, response distribution $f=0.5$ and population size $N p=107,798$ ), it was calculated using equation (1) that the minimum sample size should consist of $N_{\min }=136$ employers.

$$
N_{\text {min }}=\frac{N_{p}\left[Z^{2} \cdot f(1-f)\right]}{N_{p} \cdot e^{2}+Z^{2} \cdot f(1-f)}
$$

The sampling frame of the draw was based on the list of all entities of the Swietokrzyskie Region, compiled by the Central Statistical Office, including 107,798 employers (as of December 31, 2017). The list of economic operators used to draw the sample came from the REGON database verified using other data available via the Central Statistical Office. The use of the REGON database, as a source of data, allowed for the selection of the sample according to the assumptions concerning the target population, ensuring the appropriate quality of results. This sampling frame, however, like others, is burdened with an error due to the fact that some of the data (e.g. contact details) and its contents (liquidation of companies) are outdated, especially in the case of the smallest enterprises. Ultimately, we assumed the sample size was $n=140$ employers.

Using the formula $K=N_{p} / n$, where $N_{p}$ is the number of population elements $(107,798)$ and $n$ is the sample size (140), the value of the $K$ interval (draw interval) was determined at 767 . From the base which is the sampling frame from the Central 
Statistical Office, 140 subjects for research were selected via systematic selection ${ }^{4}$.

\section{Questionnaire Research Results}

\subsection{General statistical data}

The results presented below regards Swietokrzyskie based entities and institutions aimed at learning about employers' expectations regarding the required competences when hiring university graduates. The discussed expectations were mainly related to the skills, predispositions and individual characteristics required from the employed graduates. This involved answering the question: what aspects do you pay attention to when hiring university graduates?

This survey was conducted from March to July 2018. The research sample consisted of 140 employers representing Swietokrzyskie-based companies and other institutions, differentiated by size, time on the market and industry. The selection of the research sample was random. In the empirical research carried out, a random sample selection was assumed, on the basis of which 140 subjects were selected in a systematic selection. The return rate of the completed questionnaires was $57.45 \%$ (88), of which 81 $(92.05 \%)$ contained a full set of information, and they were subsequently subjected to statistical analysis.

With the high level of the sample implementation in mind, constant contact with the study participants was maintained. It was both a pre-notification, preparing the respondents for participation, as well as subsequent communication, mainly aimed at reminding about the survey and encouraging participants to take part in it again (reminder), as well as thanking the participants for providing feedback or the special interest of respondents resulting in asking questions about the survey itself or a follow-up for the questionnaire.

\subsection{Research sample characteristics}

The employers who took part in the questionnaire research represented many fields of operation, of which industry $(25.44 \%)$, trade $(21.05 \%)$ and services $(13.16 \%)$ were the most numerous. Figures 1 and 2 below show the proportions of distribution of particular sectors of respondents' activity.

\footnotetext{
${ }^{4}$ It consists in selecting every $K$-th element from the population - starting with the first one selected.
}

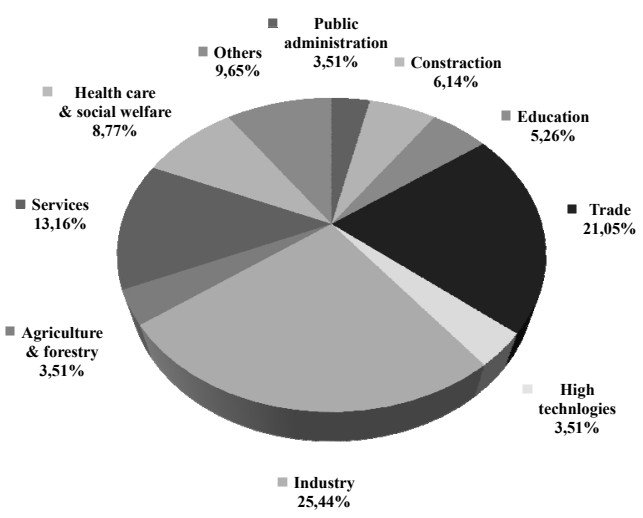

Figure 1 Research sample by sector of activity of respondents

Source: The authors' own elaboration

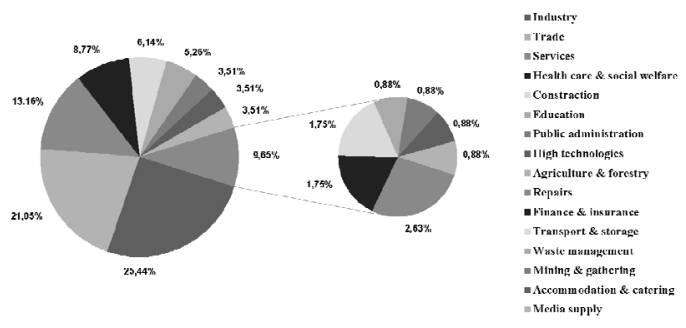

Figure 2 Research sample by sector of activity of respondents with a supporting chart Source: The authors' own elaboration

The research sample of individual companies and units, according to their size, measured by the number of employees employed, was distributed almost equally. The largest group, $29.63 \%$, were

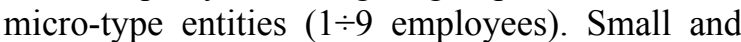
large enterprises employing $10 \div 49$ and over 250 people respectively constituted $24.69 \%$ of respondents each, as shown in Figure 3. The least representative were the so-called medium size enterprises and institutions, i.e. employing from 50 to 249 employees $(20.99 \%)$.

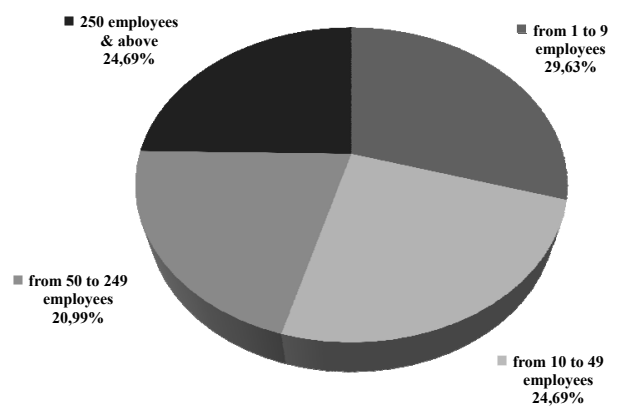

Figure 3 Research sample by number of respondents Source: The authors' own elaboration

Figure 4 presents the structure of the period of operation on the market of the enterprises. More 
than $3 / 4$ of the surveyed entities $(75.31 \%)$ have been operating on the market for many years, i.e. more than 10 years. This was followed by companies and institutions operating for 5 to 10 years $(8.64 \%), 1$ to 2 years $(7.41 \%)$ and 2 to 5 years $(6.17 \%)$. The least numerous groups were young companies, existing for less than 1 year $(2.47 \%)$.

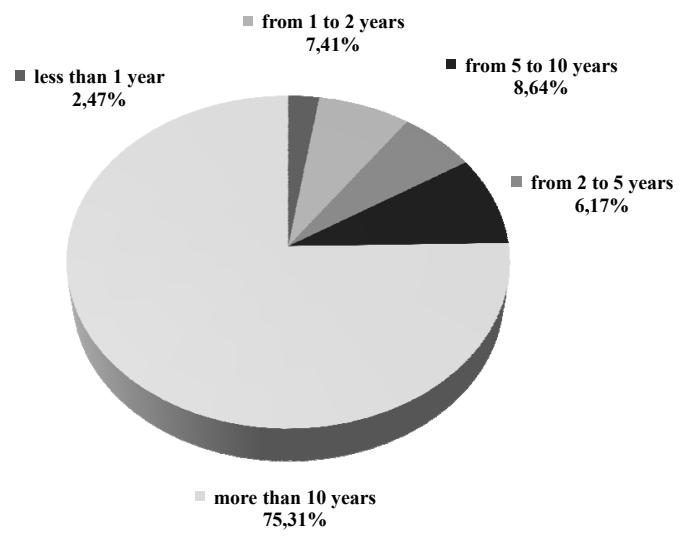

Figure 4 Research sample by period of operation of the entities on the market

Source: The authors' own elaboration

The analysis of empirical research began with the question: In the last 3 years $(2015,2016$ and 2017) have the respondents employed university graduates? It turned out that more than $3 / 4$ of employers $(75.31 \%)$ answered yes. It was a semiopen-ended (semi-close-ended) matrix question with many possible answers thanks to which information was obtained not only broken down into the years listed above, but also by the types of universities.

The respondents indicated the types of universities from which the graduates were recruited, which is presented in Figure 5. As one entity could employ graduates from different universities, the participants in the survey made one or more indications, therefore the total number of responses was 340 , i.e. more than the number of analysed questionnaires (81).

Figure 6 shows that the graduates of technical universities were employed most often, as over $1 / 4$ $(28.53 \%)$ of them were employed. In this respect, it should be borne in mind that the opinions presented later in the study will most often concern graduates from technical universities.

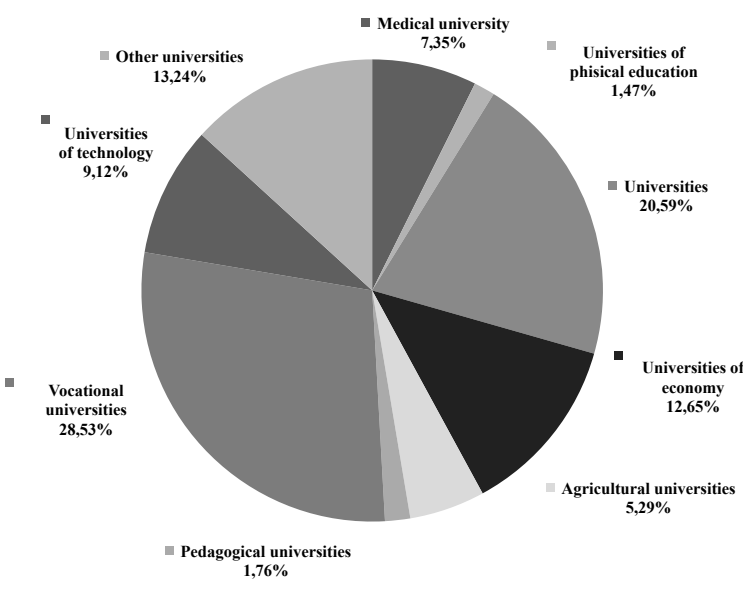

Figure 5 Structure of employed university graduates in the years $2015 \div 2017$ by type of university

Source: The authors' own elaboration

The next question was a close-ended multiplechoice (conjunctive) asking for indication of what kind of education of university graduates (general or practical) employers prefer in terms of possible employment.

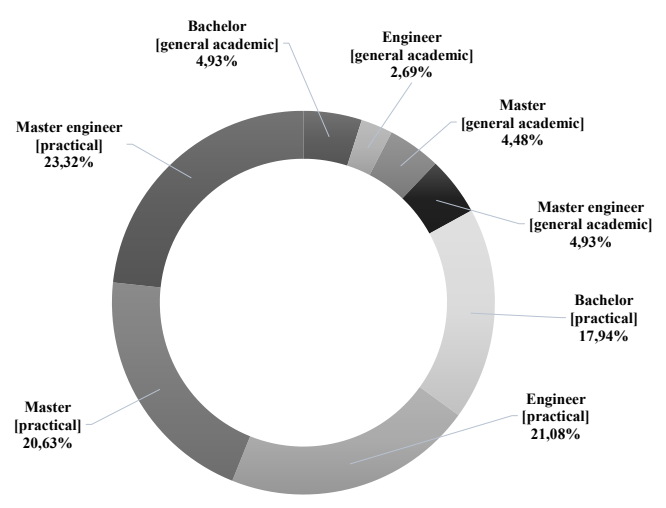

Figure 6 Preferences of employers in the area of education profile of a newly hired employee Source: The authors' own elaboration

The chart above shows that entrepreneurs are most interested in employing graduates of technical universities with a master's degree in engineering, but with a practical profile. The next place, with an almost identical result, was taken by engineers and holders of master's degrees in studies with a practical profile. The next position was taken by graduates with a bachelor's degree with a practical profile. The lowest interest among employers concerned the employment of people with general education in engineering. The total indication of the practical profile by the employers was $82.93 \%$, as shown in Figure 6 .

The questionnaire research also clearly indicated which aspects, in addition to the ones 
discussed above, are attractive to entrepreneurs when hiring graduates. It turned out that the most important factors are the acquired profession $(26.79 \%)$ and professional experience $(25.36 \%)$, as well as certificates/qualifications obtained $(20.57 \%)$ and courses and trainings completed $(17.70 \%)$ [20]. It is also interesting that for employers from the Świętokrzyskie region it is practically irrelevant whether the graduate has graduated from universities in the Świętokrzyskie region or outside of it. The grade on the diploma is also not important, as shown in Figure 7.

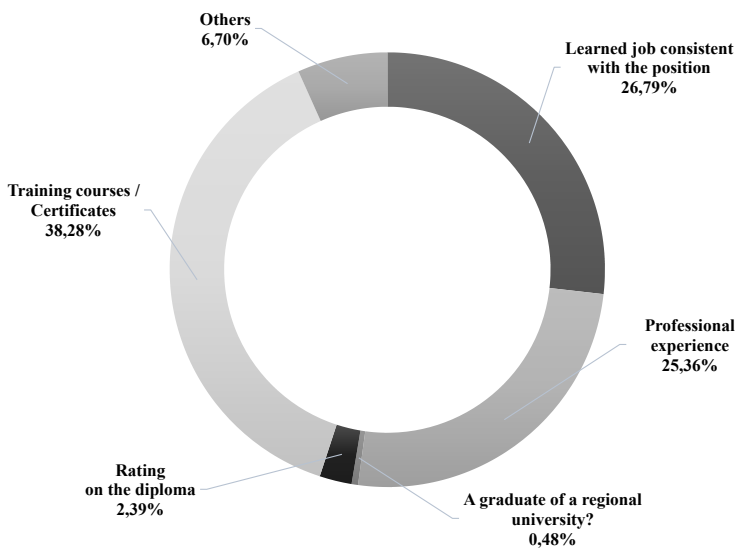

Figure 7 Important aspects when hiring graduates Source: The authors' own elaboration

\section{Conclusions and recommendations}

The questionnaire research, which is diagnostic in its nature, was carried out on a sample of 81 entities, from the Swietokrzyskie Region, of which $29.63 \%, 24.69 \%, 20.99 \%$ and $24.69 \%$, respectively, were micro, small, medium and large enterprises. The largest share of entities participating in the research were companies from the industrial sector $(25.44 \%)$. The vast majority of respondents, as much as $75.31 \%$, have been operating on the market for more than 10 years.

The analysis of the results of the empirical research allows to formulate the following conclusions:

The most numerous groups of respondents were companies and institutions from the industry, trade, services, health and social welfare, construction and education sector.

More than 3/4 of the respondents were companies and institutions operating on the market for over 10 years.
The majority of employers, $69.14 \%$, indicated that they intend to employ university graduates in the next 3 years.

Employers are most interested in hiring graduates of master of engineering studies, but what is particularly important, studies of a practical profile. Employers are most interested in hiring university graduates who have completed studies with a practical profile $(82.97 \%)$.

The employers indicated the following among the most important factors when deciding to employ a graduate:

- obtained certificates, qualifications, courses, training $(38.28 \%)$,

- acquired profession, consistent with the occupied position $(26.79 \%)$,

- professional experience (25.35\%).

The results of the company surveys indicate that when hiring a university graduate, employers pay the greatest attention to the obtained certificates, qualifications, courses and trainings. As we observe changes in the labour market, the interaction of a university with the environment requires constant monitoring of the expectations from university graduates. Therefore, it is important that the process of managing the educational offer takes into account the possibility of acquiring additional competences and skills, which constitute an added value in a competitive labour market.

It is worth emphasizing that the presented research results are consistent with the opinions of employers in other regions in Poland. For example, the results of qualitative research conducted in the Opolskie Region (individual indepth interview) at the turn of 2015 and 2016 showed that the strength of university graduates is precisely the possession of certificates of completed courses, which is a strong support when entering the labour market (Kudzia, 2017).

The research also shows that it is important for the graduates to have as much practice as possible, which is provided by studies with a practical profile, an acquired profession and professional experience. This is also confirmed by the results of qualitative research (focus group interview) conducted at the turn of 2017 and 2018 in eight large cities in Poland, i.e. Warszawa, Katowice, Poznań, Szczecin, Lublin, Olsztyn i Toruń (Turek, 2019). Employers of various industries strongly emphasized the problem of the deficit of the ability to apply knowledge into practice by candidates of higher 
education, stating the ubiquitous excess of theory over practice (Turek, 2019).SM

\section{References}

Altdorfer, P. Badilla, W. \& Bosnjak, M. (2003). Survey administration effects? A comparison of web-based and traditional written self-administered surveys using the ISSP environment module. Social Science Computer Review, 21(2), 235-243. https://doi.org/10.1177/0894439303021002009

Bartosik, A. (2017). Entrepreneurship of students. Humanities and Social Sciences, 24(1), 9-24. https://doi.org/10.7862/rz.2017.hss.1

Bartosik, A., Wiścicka, D., Kocańda, P. \& Kocańda, K. (2018). Preferences of employers of Swiętokrzyskie Voivodeship in reference to graduates of technical universities. Miscellanea Oeconomicae, 2(2), 129-140.

Etzkowitz, H. (1998). The Norms of entrepreneurial science: cognitive effects of the new university-industry, linkages. Research Policy, 27(8), 823-833. https://doi.org/10.1016/S0048-7333(98)00093-6

Kudzia, M. (2017). Opinions of employers from the Opole Province on the subject of preparing graduates of higher schools to perform professional duties (in Polish). Society and Economics, 7, 22-32. https://doi.org/10.15611/sie.2017.1.02

Kwieciński, Z. (2012). Post pedagogy (in Polish) Krakow: ORE

Mccrum-Gardner, E. (2010). Sample size and power calculations made simple. International, Journal of Therapy and Rehabilitation, 17(1), 10-14. https://doi.org/10.12968/ijtr.2010.17.1.45988

Moron, D. (2016). The impact of demographic changes on higher education in Poland (in Polish). Sc. Papers of Economic University in Katowice. Economical Studies, 290, 107-116.

\section{$\bowtie$ Correspondence}

\section{Artur Bartosik}

Kielce University of Technology

Al. Tysiaclecia P.P. 7, 25-314 Kielce, Poland

E-mail: artur.bartosik@tu.kielce.pl
Omair, A. (2014). Sample size estimation and sampling techniques for selecting a representative sample. Journal of Health Specialties, 2(4), 142-147. https://doi.org/10.4103/1658-600x.142783

Pinheiro, R., \& Antonowicz D. (2015). Opening the gates or coping with the flow? Governing access to higher education in Northern and Central Europe. Higher Education, 70, 299-313. https://doi.org/ 10.1007/s10734-014-9830-1

Statistical Yearbook of the Republic of Poland. (1990). Central Statistical Office, Warsaw: Statistical Publishing Establishment.

Statistical Yearbook of the Republic of Poland. (2006). Central Statistical Office, Warsaw: Statistical Publishing Establishment.

Statistical Yearbook of the Republic of Poland. (2011). Central Statistical Office, Warsaw: Statistical Publishing Establishment.

Statistical Yearbook of the Republic of Poland. (2016). Central Statistical Office, Warsaw: Statistical Publishing Establishment.

Statistical Yearbook of the Republic of Poland. (2019). Central Statistical Office, Warsaw: Statistical Publishing Establishment.

Turek D. (2019). The Competencies Employers Expect the Results of Qualitative Research (in Polish). Cracow Review of Economics and Management, 982, 59-76.

Wiścicka D., Bartosik A. \& Kocańda, P. (2018). General academic or professional university - preferences of employers. Miscellanea Oeconomicae, 2(2), 107-116. 